\title{
Educating Adolescents about Social Behavior using Information and Communications Technology
}

\author{
Vikas Rao Naidu ${ }^{1}$, Raza Hasan ${ }^{1}$, Raya Al-Harrasi ${ }^{1}$, and Karan Jesrani ${ }^{1}$ \\ ${ }^{I}$ Department of Computing, Middle East College, Oman \\ Correspondence Author: Raza Hasan (raza@mec.edu.om)
}

Received October 10, 2021; Revised October 28, 2021; Accepted November 01, 2021

\begin{abstract}
The media has a wide range of applications. Information and Communications Technology (ICT) plays a vital role to educate the young generation. For over three decades, we have observed a very good involvement of media in spreading awareness on various issues pertaining to society. The aim of this research study is to seek the relationship between teaching multimedia (animation) at the school level to educating adolescents about social behavior. A survey has been carried out in five different levels of educational institutions in the Sultanate of Oman. 873 samples were collected; correlation analysis was performed on hypotheses to test the linear association. Linear regression has been performed to test the hypothesis for comparing regression constants. The analysis discovered that there is adequate evidence to support the claim at the alpha level of significance that social behavior learning at school level on adolescents, multimedia effect on educating social behavior and technology-aided support on learning of social behavior has a positive and significant effect having $\alpha=0.85$, significance $F=$ 0.01 and $p$-value less than 0.05 proving to be significant.
\end{abstract}

Index Terms: Education, Human-Computer Interaction, Multimedia, Social Behavior, Technology.

\section{INTRODUCTION}

Technology plays a vital role in shaping our lives in the current era. Access to digital devices and social media usage has increased with the passage of time so does the social behaviors of the individuals. Internet where it provides the opportunity to access information for the purpose of learning as well as interacting with others, including the people they know and complete strangers. This phenomenon may affect the way adolescents behave and can have an impact on it for the rest of their lives. Virtual environments have taken over, face to face communication might not be the norm for these adolescents adversely affecting their interpersonal communication abilities.

Adolescents involved much in these virtual or online environments find it difficult to pick up the social cues due to less interpersonal communication skills and have the tendency to recognize facial indicators such as emotions, moods, and body language. Absence of gestures and body language in these virtual environments, adolescents lack the critical aspect of interacting with other human beings in real. This ability is essential when they join the workforce. They can find themselves in a situation where they might fall in a circumstance of using incorrect grammar, unable to get the attention of the listener and lack of confidence eventually abolish their prospect in the company of their carrier.

The study aimed to find the relationship of social behavior which should be taught to adolescents in their early ages using the technology which best fits with the current requirements of the teachings.

The contribution of this paper is three folds: (1) Role of learning social behavior at the school level among adolescents. (2) Role of multimedia in educating social behavior. (3) Technology aided support on learning of social behavior.

The following is a breakdown of the paper's structure: The Second Section contains the literature review. In the Third Section, the methodology is presented. The results are presented in the Fourth Section. The topic is presented in the Fifth Segment. The conclusion is reached in the Sixth Segment.

\section{LITERATURE REVIEW}

This section provides an insight into previous studies focused on three disciplines:

- First, finding that social behavior should be taught at the school level.

- Second, technology aided support on learning of social behavior.

- Lastly, multimedia influences educating social behavior.

This research is focused on middle school, high school, and university level students in the Sultanate of Oman.

Regarding social behavior teaching at the school level, previous studies have focused on applying social interactions within the classroom. Social psychological principles are integrated into the curriculum to help teachers and students [1]. Students' engagement outside the 
classroom for social interaction on their learning reflection is useful to enhance their critical thinking and problemsolving skills [2]. Character development programs can lead to a positive effect on the student's behavior that can help to excel in their lives [3]. Teachers influence their student's socio-emotional development and student's portrait their teachers as role models. The environment provided to them should be relaxed and concentration appears to be more helpful in managing student behavior and motivating students [4]. The literature studied to find out social behavior teaching at the school level was found essential as the literature directed towards the impact.

Educational technology tools help students to improve their skills for both communication and language skillset which is essential for their employment [5]. According to a study, e-learning media has a considerable and favorable effect on the majority of students' social skills augmentation [6]. Information and Communications Technology (ICT) supports the usage of technology for improving the teaching and learning processes [7]. Radical increases in using technology especially in younger generations are on the rise as teenagers spend more time on media at their early ages [8]. This can help teachers to disseminate knowledge and information to students and can be able to track the interactions to enhance the learning process.

Several studies were conducted based on the technological effects on face-to-face and social interactions via mobile phones which become a culture now. Social media postings have significantly increased linking to person-toperson relationships and personal relationships [9]. Video games have also contributed to affecting the interpersonal skills of individuals [10]. The author refutes the notion that adolescent well-being is badly impacted by their constant use of digital technology [11]. It is evident from the conducted studies that technology can give students more control i.e., shifting from a teacher-oriented to a studentoriented learning approach. It's a matter of adopting the technology for the educational institution for effective and efficient design of learning applications [12].

Many researchers believe that multimedia using ICT helps to understand complex concepts with ease and it provides the facility for students to reach out anytime anywhere [12] and [13]. Multimedia covers a wide variety of techniques by educators to transfer the concepts such as videos, animation, games, virtual reality, augmented reality, etc. [14]. Animation interactivity is easily understood by novice learners and is pleasant to watch [15-17]. Adolescents take influence from the animated character of their penchant such as boys want action, whereas girls prefer fairy characters [18-21]. Animated cartoons are one of the major influences on a person's youth, and they may help in the development of a well-balanced youngster with good mental health [22]. Cartoon animation has a great impact on teenagers' minds and facilitate learning of right behaviors [23]. For this reason, multimedia animation is selected as it serves the purpose with maximum utilization on learning good social behaviors.

It is evident from the literature review that social behavior should be taught at the school level either through curriculum or with the aid of technology. Technology aided support on learning of social behavior and lastly, multimedia especially animation influences educating social behavior in adolescents.

\section{METHODOLOGY}

The investigation is exploratory in character. The study employs a quantitative approach. For the purpose of study, three private schools and one Higher Education Institution (HEI) within the Sultanate of Oman were chosen. To carry out this research, it has been split into three phases. Firstly, design and implement the animated video through an interactive DVD, authoring of which was done based on Human Computer Interaction (HCI) principles. To accomplish this task, a set of multimedia tools were selected which are freely available. However, few tools that are also meant for commercial purposes, their respective educational (student) edition was used, since the output of this research aims to be used solely for educational purposes only. The tools in three categories are - Freeware, Freemium, and Free and Open Source. Where freeware is an open-access tool, freemium are tools that can be used with limited capabilities. On the other side, free and open-source software is available free of cost. In addition, they can be customized by any user [24]. Here, the student edition of 3D modeling and animation tools were used. One freemium tool was used for Story-Board design, whereas, initial character sketch was developed using a free and open-source tool. The final composition, sound mixing, video editing, and DVD authoring was done in licensed software from the 'Adobe CC' package.

Secondly, designing the questionnaire required answering the conducted research. Lastly, conducting the questionnaire session after using the multimedia animation.

\section{A. Research Model and Hypotheses}

For this purpose, extensive meetings were conducted with a Senior Psychologist working in one of the private HEIs in Oman. This helped us identify the course of our research and facilitate modeling of the research hypotheses:

H1: Social behavior learning at the secondary school level will have a favorable and meaningful influence on adolescents.

H2: Multimedia has a big and positive impact on educating social behavior.

H3: Technology-aided support has been learned to have a positive and important impact on social behavior.

\section{B. Character Design and Modeling}

The initial stage of design and modeling started with a basic plan. The process began with, drawing the sketch of a '3D Character' as shown in Figure 1. The character was designed using a free and open-source tool named 'Pencil2D'. This free and open-source tool used here provided easy customization, cross-platform compatibility, and cost-effectiveness to the design process and thus benefitted the entire research [25].

The character was drawn digitally from the Front and the Left view, and then imported into '3D Modeling' tools, 'Autodesk 3DS Max' and 'Autodesk Maya', where 
modeling was done using the 'Edit Poly' technique. The character was modeled with a low number of polygons in it. It was intentionally done to keep the structure of the body simple to animate with very less amount of processing power involved.

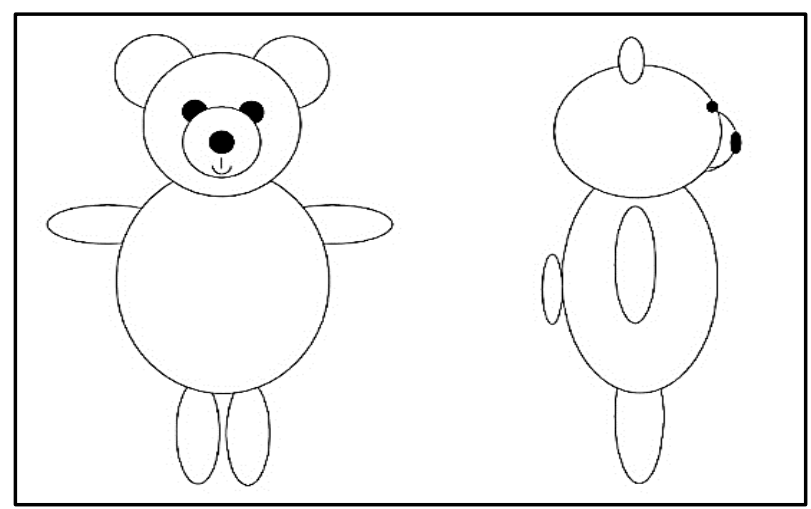

Figure 1: Character Sketch

The Figure 2 shows the four viewports of the tool displaying the modeling of the character from Front, Top, Left, and Perspective angles. After the modeling was done, other characters were modeled, and finally texturing was done. The next process that was followed was, rigging the characters and skinning them with bones (endoskeleton, that enables a 3D character to animate realistically). A free educational version (student version) of this tool was used for this purpose.

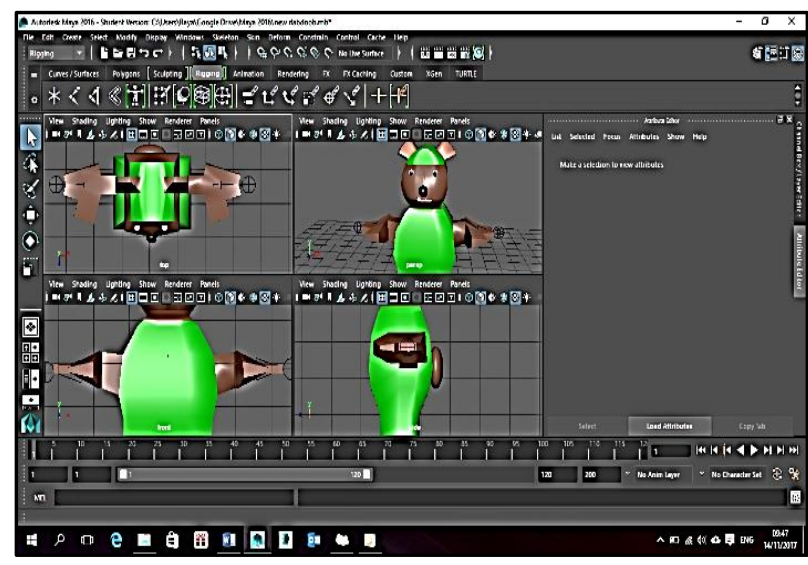

Figure 2: Designing of 3D Character

\section{Planning of Animated Video through Story-Board}

As a design part of this study, it was planned to develop the animated videos in 3D as shown in Figure 3.

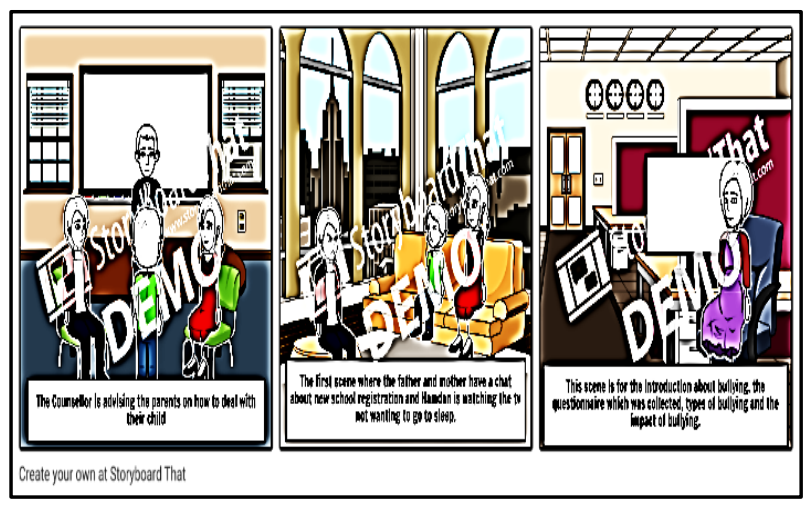

Figure 3: Designing of Video through Story-Board
A free tool, named 'Storyboard' that was used, for designing the Story-Board of this animation. To keep the budget of the production to the lowest, the demo version of this tool was utilized and hence it resulted in output with a watermark. However, since the Story-Board is just meant for reference purposes, this tool was good enough. Based on the Story-Board, various changes were made in the final plot and script of the video, and the final process of animation was done in 'Autodesk Maya'.

\section{Animated Video Development}

Animated video was developed by using 'Autodesk Maya' as shown in Figure 4 and Figure 5. Here also, a free educational version was utilized for developing the animation. As shown in the following figure, the ambiance of the scene was well lit by means of virtual lights, and various perspectives of the scenes were captured through $3 \mathrm{D}$ cameras in the software. The scene depicts the counseling session of the main character regarding social behavior among peers.

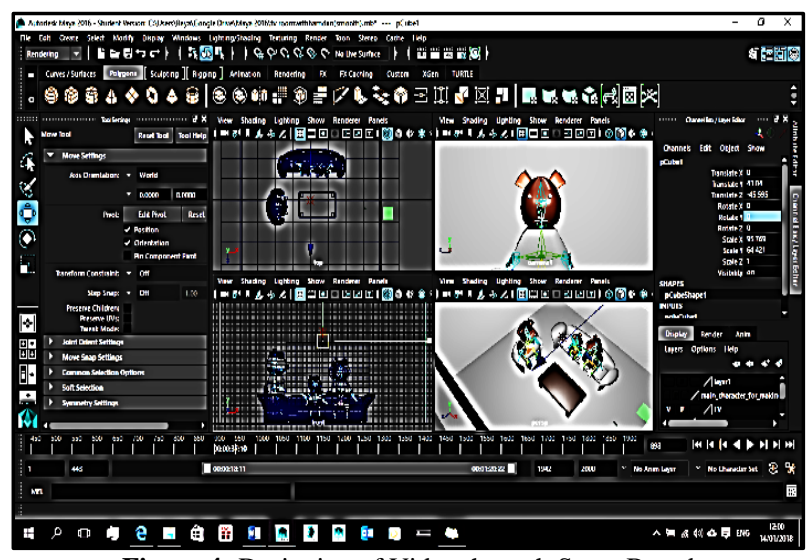

Figure 4: Designing of Video through Story-Board

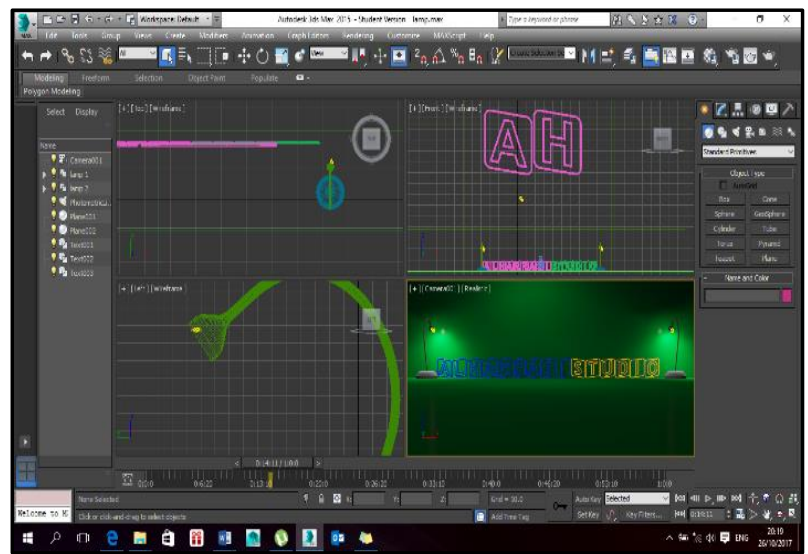

Figure 5: Animated Video Development using Autodesk 3Ds Max

To provide a more cinematic and appealing effect, title animation was also developed for this animation. This was designed and animated in 'Autodesk 3DS Max'.

The final output was rendered in MJPEG compressed standard format video in high quality after which sound mixing and voice-over were provided. This was done using video editing software 'Adobe Premiere'. The final output was rendered in Full HD (1920x 1080) resolution in H.264 format as this is the most used video format for highquality videos on multiple platforms at present. 


\section{E. Interactive Design for the Final Delivery}

The interactive multimedia system is well structured if it is in accordance with certain guiding principles of HCI. Even for this animated video, it was decided to deliver it in an interactive DVD package format, apart from digital files. There are 10 general rules of thumb and hence called 'Heuristics', first defined in the year 1994 by 'Jacob Nielson'. These Heuristics are generally considered to be the guidelines for most of the interactive system interface designs, however, based on a different scenario and different requirements, they could be even overruled [26]. The HCI principles play a quite vital role in e-learning content design based on various levels of studies. For example, the aesthetic elements including color combination for an interactive application for school level study will be different than that at the higher education level one. Therefore, the HCI considerations are different for different requirements. The designer must ensure aesthetics and minimalistic design for the e-learning solution design [27] and [28]. Some of these guiding principles were used during this research and its design and implementation phase:

a) Visibility of the Status:

This principle states that the system must provide a status of what is going on in a transparent manner. It should provide the visibility of system status to the end-user and clearly provide a status if it's online/offline/ready to use (or) not - ready to use. To ensure this, the authors have designed the user interface using 'Sony DVD Architect 4.0' which is a DVD authoring tool as shown in Figure 6.

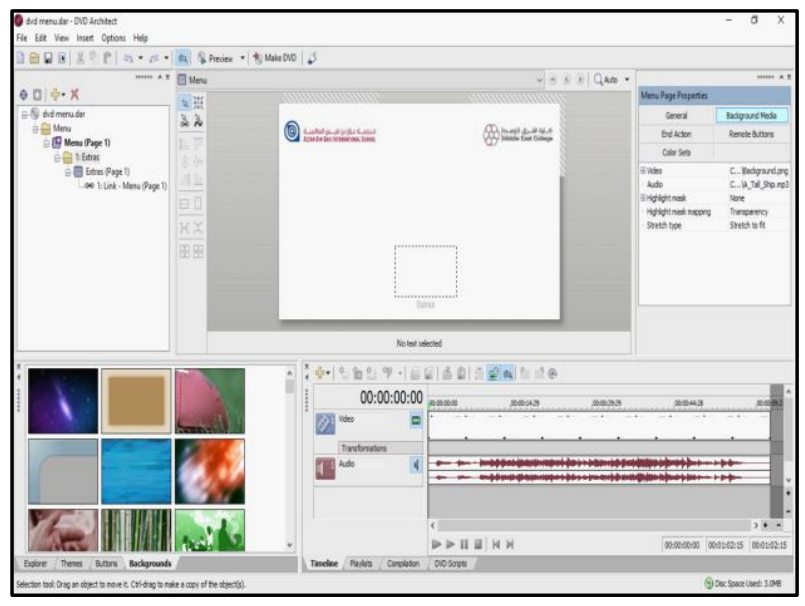

Figure 6: User Interface Design

This tool offers various customization options, including menu-based navigation control, colorful interface customization options, different audio and subtitle streams, and many more. This was authored for the purpose of visibility of the status of the interactive learning system after inserting the media in the player.

b) Navigation and Control in Interactive Design: Navigation and control are the key elements in an interactive application. Every application has its own way of defining this and in 'DVD Architect', it is done through the property window as shown in Figure 7.

\begin{tabular}{|c|c|}
\hline & enen $\wedge x$ \\
\hline \multicolumn{2}{|l|}{ Button Properties } \\
\hline Transformations & Action \\
\hline Media & Highlight \\
\hline Navigation & Color Sets \\
\hline Command & Link \\
\hline Destination & InThe \\
\hline Destination chapter & 1: Scene/Chapter \\
\hline Destination button & $N / A$ \\
\hline Set audio track & No change \\
\hline Set subtitle track & No change \\
\hline Set video angle & No change \\
\hline Auto-activate & No \\
\hline
\end{tabular}

Figure 7: Interactive Design

The control from the home page can be navigated to other pages containing media through various buttons. As seen in the previous section, buttons were defined to navigate through. These buttons are linked by setting their destination. While navigating from one page to another, the changes in audio tracks (English / Arabic) were set up through the control given here.

c) Flexibility in Access:

This principle was the key guiding element since the final output is supposed to be accessed by the audience at various levels. Hence, the interface was designed in such a way that both novice and experienced users can access it with ease without any issues. The buttons and other elements in the interface are easy to access by all and hence provide accessibility for everyone, irrespective of their experiences.

\section{F. Instrument Design}

A questionnaire is created and utilized to collect data. A survey approach is combined with a quantitative method. We designed a questionnaire split into two categories such as socio-economic information and psychometric scale.

a) Socio-Economic Information:

Socio-economic information such as demographic data was collected. That includes Gender (Male/Female), Age (11-13, (14-18, 19-25, Above 25), and Education (Middle School, High School, University, Professional).

b) Psychometric Scale:

The questionnaire psychometric scale comprises of four questions or statements. The five-point rating scale was used for the questionnaire.

Q1: To what extent do you think that social behavior should be taught at the school level.

Q2: Repercussion of unsuitable behavior should be communicated through the use of media.

Q3: To what extent do you think multimedia could play a vital role in distribution. 
Q4: Technology could be used as an aid to support educating adolescents.

\section{G. Data Collection}

Ethical approval is necessary for data collection purposes. The consent was obtained from the participants in this study by presenting the study's goal and description to them. It was also communicated, and the study is of "no potential risk" and in case of any discomfort they can withdraw their participation at any given moment of time as it is voluntary participation. Privacy and confidentiality have been the utmost priority in the study. The data and information collected in this study were anonymously taken, no identification information has been discussed when reporting the data. The data is not stored and will be destroyed once the analysis has been performed. The data was collected from Spring 2019 to Fall 2019 and 873 observations were used for the study.

\section{a) Data Cleansing:}

Data cleansing is performed to eliminate unnecessary data and separate data which is relevant for analysis in the study such as gender, age, and education.

b) Data Partitioning:

The Psychometric Scale was mapped with numerical values such that it can be useful for statistical analysis. 'Strongly Disagree' was denoted by 0, 'Disagree' denoted by 1 , 'Neutral' denoted by 2 , 'Agree' denoted by 3 , and 'Strongly Agree' was denoted by 4.

\section{RESULTS}

The researchers put through 4 variables with regards to the hypotheses. The descriptive statistics of the research variables in terms of the frequency distribution are presented in Table 1.

Animated video was developed by using 'Autodesk Maya' as shown in Figure 4 and Figure 5. Here also, a free educational version was utilized for developing the animation. As shown in the following figure, the ambiance of the scene was well lit by means of virtual lights, and various perspectives of the scenes were captured through $3 \mathrm{D}$ cameras in the software. The scene depicts the counseling session of the main character regarding social behavior among peers.

\begin{tabular}{|l|l|c|c|}
\multicolumn{4}{|c}{ Table 1: Distribution of Frequencies } \\
\hline \multirow{3}{*}{ Question } & \multicolumn{1}{|c|}{ Options } & N & $\%$ \\
\hline \multirow{3}{*}{ Gender } & Male & 399 & 46.94 \\
\cline { 2 - 4 } & Female & 474 & 55.64 \\
\hline \multirow{4}{*}{ Age } & $11-13$ & 290 & 33.22 \\
\cline { 2 - 4 } & $14-18$ & 107 & 12.26 \\
\cline { 2 - 4 } & $19-25$ & 178 & 20.39 \\
\cline { 2 - 4 } & Above 25 & 298 & 34.14 \\
\hline \multirow{4}{*}{ Education } & Middle School & 290 & 33.22 \\
\cline { 2 - 4 } & High School & 107 & 12.26 \\
\cline { 2 - 4 } & University & 273 & 31.27 \\
\cline { 2 - 4 } & Professional & 203 & 23.25 \\
\hline \multirow{2}{*}{ Q1 } & Strongly Agree & 401 & 45.93 \\
\hline
\end{tabular}

\begin{tabular}{|l|l|c|c|}
\hline \multirow{5}{*}{} & Agree & 418 & 47.88 \\
\cline { 2 - 4 } & Neutral & 0 & 0.00 \\
\cline { 2 - 4 } & Disagree & 54 & 6.19 \\
\cline { 2 - 4 } & Strongly Disagree & 0 & 0.00 \\
\hline \multirow{5}{*}{ Q2 } & Strongly Agree & 197 & 22.57 \\
\cline { 2 - 4 } & Agree & 384 & 43.99 \\
\cline { 2 - 4 } & Neutral & 163 & 18.67 \\
\cline { 2 - 4 } & Disagree & 129 & 14.78 \\
\cline { 2 - 4 } & Strongly Disagree & 0 & 0.00 \\
\hline \multirow{5}{*}{ Q4 } & Strongly Agree & 264 & 30.24 \\
\cline { 2 - 4 } & Agree & 307 & 35.17 \\
\cline { 2 - 4 } & Neutral & 198 & 22.68 \\
\cline { 2 - 4 } & Disagree & 104 & 11.91 \\
\cline { 2 - 4 } & Strongly Disagree & 0 & 0.00 \\
\hline \multirow{5}{*}{} & Strongly Agree & 244 & 27.95 \\
\cline { 2 - 4 } & Agree & 576 & 65.98 \\
\cline { 2 - 4 } & Neutral & 0 & 0.00 \\
\cline { 2 - 4 } & Disagree & 53 & 6.07 \\
\cline { 2 - 4 } & Strongly Disagree & 0 & 0.00 \\
\hline
\end{tabular}

Table 2 presents the descriptive statistics of the research mean, standard error, median, mode, and standard deviation of variables.

Table 2: Descriptive Statistics

\begin{tabular}{|c|c|c|c|c|c|}
\hline Q\# & Mean & $\begin{array}{c}\text { Standard } \\
\text { Error }\end{array}$ & Median & Mode & $\begin{array}{c}\text { Standard } \\
\text { Deviation }\end{array}$ \\
\hline Q1 & 3.336 & 0.026 & 3 & 3 & 0.771 \\
\hline Q2 & 2.743 & 0.033 & 3 & 3 & 0.969 \\
\hline Q3 & 3.158 & 0.024 & 3 & 3 & 0.706 \\
\hline Q4 & 2.837 & 0.034 & 3 & 3 & 0.990 \\
\hline
\end{tabular}

Table 3 presents the reliability, ANOVA: Two-Factor without Replication is carried out, which can aid in the calculation of Cronbach's alpha.

Table 3: ANOVA: Two-Factor Without Replication

\begin{tabular}{|c|c|c|c|c|c|c|}
\hline 产节 & 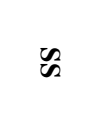 & 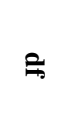 & 光 & $x$ & 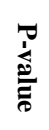 & $\stackrel{9}{3}$ \\
\hline Rows & 1810.04 & 872 & 2.08 & 6.65 & 0.0 & 1.09 \\
\hline Columns & 199.52 & 3.0 & 66.51 & 213.15 & 0.0 & 2.61 \\
\hline Error & 816.23 & 2616 & 0.31 & & & \\
\hline Total & 2825.79 & 3491 & & & & \\
\hline
\end{tabular}

The formula for calculating Cronbach's alpha is given below:

$$
\alpha=\operatorname{Rows}(M S) / \text { Error }(M S)
$$

Cronbach's alpha value was found to be $=0.85$ using Eq. (1). Table 4 shows the covariance to see if the variables are pointing in the same direction. 


\begin{tabular}{|c|c|c|c|c|}
\hline \multicolumn{5}{|c|}{ Table 4: Covariance Analysis } \\
\hline Q\# & Q1 & Q2 & Q3 & Q4 \\
\hline Q1 & 0.594 & & & \\
\hline Q2 & 0.297 & 0.938 & & \\
\hline Q3 & 0.450 & 0.656 & 0.979 & \\
\hline Q4 & 0.430 & 0.403 & 0.407 & 0.497 \\
\hline
\end{tabular}

Table 5 shows the correlation between the variables to ensure that they are all valid.

Table 5: Correlation Analysis

\begin{tabular}{|c|c|c|c|c|}
\hline Q\# & Q1 & Q2 & Q3 & Q4 \\
\hline Q1 & 1 & & & \\
\hline Q2 & 0.398 & 1 & & \\
\hline Q3 & 0.590 & 0.684 & 1 & \\
\hline Q4 & 0.792 & 0.589 & 0.583 & 1 \\
\hline
\end{tabular}

The summary of the Linear Regression model is shown in Table 6.

\begin{tabular}{|c|c|}
\hline \multicolumn{2}{|c|}{ Table 6: Model Summary } \\
\hline Regression Statistics & Values \\
\hline Multiple R & 0.769 \\
\hline R Square & 0.591 \\
\hline Adjusted R Square & 0.590 \\
\hline Standard Error & 0.634 \\
\hline Observations & 873 \\
\hline
\end{tabular}

Predictors: (Constant), Q1, Q2, Q3

The analysis of variance is shown in Table 7.

\begin{tabular}{l}
\begin{tabular}{|l|c|c|c|c|c|}
\hline \multicolumn{1}{|c|}{ Model } & df & SS & MS & F & $\begin{array}{c}\text { Significance } \\
\text { F }\end{array}$ \\
\hline Regression & 3 & 505.58 & 168.53 & 419.23 & $0.01^{\text {b }}$ \\
\hline Residual & 869 & 349.33 & 0.40 & & \\
\hline Total & 872 & 854.90 & & & \\
Predictors: (Constant), Q1, Q2, Q3. ${ }^{\text {b }}$ Dependent Variable: Q4
\end{tabular} \\
\hline
\end{tabular}

Table 8 presents the equation variables.

Table 8: Equation Variables

\begin{tabular}{|l|c|c|c|c|}
\hline & Intercept & Q1 & Q2 & Q3 \\
\hline Coefficients & -0.20 & 0.57 & 0.58 & -0.15 \\
\hline $\begin{array}{l}\text { Standard } \\
\text { Error }\end{array}$ & 0.10 & 0.05 & 0.03 & 0.06 \\
\hline t Stat & -1.98 & 12.48 & 20.99 & -2.61 \\
\hline P-value & 0.05 & 0.00 & 0.00 & 0.01 \\
\hline Lower 95\% & -0.405 & 0.484 & 0.527 & -0.261 \\
\hline Upper 95\% & -0.002 & 0.665 & 0.636 & -0.037 \\
\hline
\end{tabular}

Dependent Variable: Q4

\section{DISCUSSION}

The analysis is based on 873 observations as shown in Table 1, the responses recorded by females $55.64 \%$ and male $46.94 \%$. Respondents' age ranges from 11 and above and are related to the education sector either students, teachers, or professionals engaged with the education sector. Student age responses recorded by categories of 11 $13(33.22 \%), 24-18(12.26 \%), 19-25(20.39 \%)$, above 25 (34.14\%). Respondent's age was classified with education, responses recorded for Middle School (33.22 $\%)$, High School (12.26 \%), University (31.27\%), and Professional $(23.25 \%)$. From the frequency statistics, female participation is slightly higher than males. Age and education-wise distribution show similar participation of the respondents. Respondents' response shows highly positive and agrees on to what extent do you think that social behavior should be taught at the school level i.e. Q1 $(92.81 \%)$, which is in line with our first hypothesis. Respondents' response shows positively and agrees on the Repercussion of unsuitable behavior should be communicated through the use of media i.e. Q2 (66.56\%), which is in line with our first hypothesis. Respondents' response shows positively and agrees on to what extent do you think multimedia could play a vital role in distribution i.e. Q3 (65.41\%), which is in line with our second hypothesis. Respondents' response shows positively and highly agreeing on technology could be used as an aid to support for educating the adolescents i.e. Q4 (93.93\%), which is in line with our third hypothesis.

Also, to verify the frequency distribution, further statistical analysis using mean, median, and mode were calculated as shown in Table 2. Mean for Q1, Q2, Q3, and Q4 are 3.336, $2.743,3.158$, and 2.837 respectively. The result shows that the respondents agree with the questions asked in the questionnaire given the median and mode as 3 . The standard deviation for Q1, Q2, Q3, and Q4 is 0.771, 0.969, 0.706 , and 0.990 respectively. The standard deviation reveals how near the data points are to the mean.

Furthermore, ANOVA: Two-Factor without Replication is done to calculate Cronbach's alpha as shown in Table 3 and Eq. (1). Cronbach's alpha is a statistical method for determining how closely a bunch of things is related. The alpha coefficient for the four items was $=0.850$, indicating that they have a high level of internal consistency $(>0.70)$. Additionally, we investigated the dimensionality of scale using covariance analysis as shown in Table 4. The covariance suggests that the items or variables are unidirectional. Q1 covariance is 0.594 and corresponding items is having less covariance. Similarly, it can be looked for other Q2, Q3, and Q4 shows less covariance than Q1. Moreover, correlation analysis is done to evaluate the strength of the relationship between two or more quantitative variables as shown in Table 5. For those who responded in the survey, Q1 was correlated with Q3 scores, $\mathrm{r}=.59$ which can be considered as a large effect. Similarly, Q1 was correlated with higher importance with Q4 scores, $\mathrm{r}=.0 .79$ which can be considered as a large effect. Q2 was correlated with higher importance with Q3 scores, $r=.68$ which can be considered as a large effect. Similarly, Q2 was correlated with higher importance with Q4 scores, $\mathrm{r}=.0 .58$, which is deemed a significant effect. Q3 was associated with a higher relevance of $\mathrm{Q} 2$ scores ( $\mathrm{r}=.0 .68)$, which is a significant impact. Similarly, Q3 was correlated with higher importance with Q4, r=.0.58 which can be considered as a large effect. Only, Q1 correlated with less importance with Q2 scores, $\mathrm{r}=.0 .39$ which can be 
considered as a reduced effect. This is evident that if social behavior is taught at the school level, so it is having the least chance that it must be taught again but it is considered due to the importance of this research.

Besides, correlation analysis we can't infer the same correlation to the rest of the population from which our samples are derived until we do a test for significance. For this purpose, linear regression analysis is done as shown in Table 6. The correlation coefficient, or multiple ' $R$ ', is a measurement of the strength of a linear relationship between two variables. The value of 0.769 indicates a strong positive association. The coefficient of determination, or ' $R$ ' Square, is a measure of how well a model fits. It displays the number of points that fall on the regression line. ' $R$ ' Square 0.591 means that half of the variance in the outcome variable is explained by the model. This is due to the predictors are trending linearly in terms of the response variable, which makes the ' $t$ ' values significant; however, the ' $R$ ' squared is low since the errors are substantial, implying that the data variability and therefore the regression is large. Another goodness-of-fit metric that demonstrates the precision of the regression analysis is the standard error, 0.634 suggests that the regression equation is precise due to the less standard error. Table 7 represents the analysis of variance (ANOVA) Significance ' $F$ ' is 0.01 which is less than 0.05 suggesting our linear regression model is ok. This can also be verified by Table 8 P-value of Q1 (0.00), Q2 (0.00), and Q3 (0.01).

\section{CONCLUSION}

In this study, we try to establish the connection between social behavior and the use of technology. Firstly, we tested the hypothesis that social behavior should be taught at the school level. Secondly, we tested the hypothesis of what tools can have an impact on learning. Lastly, we tested the hypothesis on the role of technology can provide a better learning aid for teaching and learning social behavior.

From the descriptive analysis, we found that the hypotheses claimed to have an impact on the said study but were not conclusive. Cronbach's alpha is used to determine the survey's reliability. The alpha coefficient was equal to 0.85 , indicating that the items are internally consistent. Covariance analysis was performed to investigate the dimensionality and found that Q1 and Q4 have less covariance compared to Q2 and Q3 which are having high covariance. Correlation analysis is done to evaluate the strength of the relationship between two or more quantitative variables. Result suggests Q1, Q3, and Q4 are highly correlated. Q2 was having less correlation as that relates to the teaching of social behavior after the student is mistreated. The correlation analysis supports the claims of the hypotheses tested. Linear regression is then performed and found Q4 as the dependent variable and the rest was independent variables having significance ' $F$ ' of 0.01 .

At the alpha level of significance, there is adequate evidence to support the premise that social behavior learning in school will have a favorable and substantial influence on teenagers.

In addition, at this level of significance, with the support of pieces of evidence to support the claim that multimedia elements such as animation and videos have a positive and significant effect on educating social behavior.

Lastly, there is also sufficient evidence at the alpha level of significance to support the claim that technology-aided support has a positive and significant effect on learning social behavior.

Nonetheless, this study has limitations, such as viewing the findings as an early investigation of utilizing ICT to teach adolescents about social conduct in a school setting. More particular indicators, such as socioeconomic status, access, equipment, and so on, should be examined to assist us to acquire a better understanding of adolescents' social behavior. As a result, making it is easier to design policies and procedures that will help to educate adolescents in a better way. Multimedia can be used to strengthen social skills therapies interventions with students having emotional and behavioral issues in order to develop adaptive behavior, transfer role play to the real world, and enhance learning by observations.

In the future, a survey or an interview can be conducted to find the efficiency and efficacy of multimedia (animation) on the student's behavior for the wellbeing of society.

\section{Acknowledgment}

The authors would like to thank Almighty for his blessings throughout this research. Thanks to the family members for their support. Special thanks to all the participants who helped with their inputs in the survey of this research which was the key element.

\section{Author Contributions}

Vikas Rao Naidu contributed to the investigation and project administration. Raza Hassan contributed to the supervision. Raya Al-Harrasi contributed to the visualization, collected data, and conducted the preprocessing of the input data. Karan Jesrani contributed to the resources and writing, review, and editing. All authors have read and agreed to the published version of the manuscript.

\section{Conflict of Interest}

The authors declare no conflict of interest.

\section{Data Availability Statement}

The datasets generated during and/or analyzed during the current study are available from the corresponding author on reasonable request.

\section{Funding}

This research received no external funding.

\section{References}

[1] Gehlbach, H. (2010). The social side of school: Why teachers need social psychology. Educational Psychology Review, 22(3), 349362.

[2] Hurst, B., Wallace, R. R., \& Nixon, S. B. (2013). The impact of social interaction on student learning. Reading Horizons. 
[3] Thompson, W. G. (2002). The effects of character education on student behavior. East Tennessee State University.

[4] Marcella, J., \& Howes, C. (2014). Using naturalistic observation to study children's engagement within early childhood classrooms. Handbook of Research Methods in Early Childhood Education Volume 2: Review of Research Methodologies, 25.

[5] Kasapoğlu-Akyol, P. (2010). Using educational technology tools to improve language and communication skills of ESL students. Novitas-Royal, 4(2).

[6] Khan, R. U., Inamullah, H. M., \& Irshadullah, H. M. (2018). Effects of E-Learning Media on Cognitive Skills Enhancement of Students. Global Social Sciences Review, 3(1), 175-192.

[7] Sangrà, A., \& González-Sanmamed, M. (2010). The role of information and communication technologies in improving teaching and learning processes in primary and secondary schools. Australasian Journal of Educational Technology, 26(8).

[8] Roberts, D. F. (2005). Generation M: Media in the lives of 8-18 year-olds. Henry J. Kaiser Family Foundation.

[9] Orben, A., Dienlin, T., \& Przybylski, A. K. (2019). Social media's enduring effect on adolescent life satisfaction. Proceedings of the National Academy of Sciences, 116(21), 10226-10228.

[10] AK, P. (2010). Rigby CS. Ryan RM. A motivational model of video game engagement. Rev Gen Psychol, 14, 154-166.

[11] Orben, A., \& Przybylski, A. K. (2019). The association between adolescent well-being and digital technology use. Nature Human Behaviour, 3(2), 173-182.

[12] Lieshout, M., Egyedi, T., \& Bijker, W. (2018). Social Learning Technologies: The introduction of multimedia in education. Routledge.

[13] Lester, J., Klein, C., Rangwala, H., \& Johri, A. (2017). Learning Analytics in Higher Education: ASHE Higher Education Report. John Wiley \& Sons.

[14] Huang, H. M., Rauch, U., \& Liaw, S. S. (2010). Investigating learners' attitudes toward virtual reality learning environments: Based on a constructivist approach. Computers \& Education, 55(3), 1171-1182.

[15] Xiao, L. (2013). Animation trends in education. International Journal of Information and Education Technology, 3(3), 286.

[16] Wang, P. Y., Vaughn, B. K., \& Liu, M. (2011). The impact of animation interactivity on novices' learning of introductory statistics. Computers \& Education, 56(1), 300-311.

[17] DeCoursey, C. A. (2012). Trialing cartoons: Teachers' attitudes towards animation as an ELT instructional tool. Computers \& Education, 59(2), 436-448.

[18] Ruchi, V., \& Sunita, M. Effect of Animation on Concept Formation of Students from Government and Private Schools between the Age Group of 7-11 Year.

[19] Hasan, R., Palaniappan, S., Mahmood, S., Sarker, K. U., Sattar, M. U., Abbas, A., ... \& Rajegowda, P. M. (2021). eDify: Enhancing Teaching and Learning Process by Using Video Streaming Server. International Journal of Interactive Mobile Technologies, 15(11).

[20] Al Mahdi, Z., Naidu, V. R., \& Kurian, P. (2019). Analyzing the Role of Human Computer Interaction Principles for E-Learning Solution Design. In Smart Technologies and Innovation for a Sustainable Future (pp. 41-44). Springer, Cham.

[21] Vaidhyanathan, N., Haroun, T., Naidu, V. R., Hasan, R., Reales, L., \& Jesrani, K. (2021). Proposed E-Learning Framework For Special Need Students In Higher Education Institutions. IJAEDUInternational E-Journal of Advances in Education, 7(20), 131-141.

[22] Habib, K., \& Soliman, T. (2015). Cartoons' effect in changing children's mental response and behavior. Open Journal of Social Sciences, 3(09), 248.

[23] Ghilzai, S. A., Alam, R., Ahmad, Z., Shaukat, A., \& Noor, S. S. (2017). Impact of cartoon programs on children's language and behavior. Insights in Language Society Culture, 2, 104-126.

[24] Mohammed, Q. A., Naidu, V. R., Hasan, R., Mustafa, M., \& Jesrani, K. A. (2019). Digital Education using Free and Open Source Tools to Enhance Collaborative Learning. International E-Journal of Advances in Education, 5(13), 50-57.

[25] Naidu, V. R., Singh, B., Al Harrasi, R. A., \& Al Balushi, H. H. (2017). Technology Enhanced Learning Assisted By Free And Open Source Software. IJAEDU-International E-Journal of Advances in Education, 3(8), 422-427.
[26] Nielsen, J. (10). Heuristics for User Interface Design: Article by Jakob Nielsen, 1995. Retrieved 2016-06-10, from http://www. nngroup. com/articles/ten-usability-heuristics.

[27] Hasan, R., \& Mahmood, S. (2012, September). Survey and evaluation of simulators suitable for teaching for computer architecture and organization Supporting undergraduate students at Sir Syed University of Engineering \& Technology. In Proceedings of 2012 UKACC International Conference on Control (pp. 10431045). IEEE.

[28] Khan, I. U. (2021). Comparitative analyis of IPVE \& IPV6 intended for learning object repository to setup an e-learning environment. Sir Syed University Research Journal of Engineering \& Technology, 11(01). 